\title{
Prestasi Belajar Mengoperasikan Program Pengolahan Angka Melalui Model Pembelajaran Bertukar Pasangan Siswa SMKN 1 Rengat
}

\author{
Arminiyetti ${ }^{1}$ \\ ${ }^{1}$ SMK Negeri 1 Rengat \\ e-mail: ${ }^{1}$ arminyetti1@gmail.com
}

\begin{abstract}
Abstrak
Tujuan dari penelitian ini adalah untuk meningkatkan hasil belajar siswa terhadap matadiklat mengoperasikan program pengolahan angka melalui model pembelajaran bertukar pasangan pada siswa kelas XI Akuntasi SMK Negeri 1 Rengat .jenis penelitian yang diguanakan adalah penelitian tindakan kelas yang dilaksanakan dalam 3 siklus. Subjek dalam penelitian ini adalah peserta didik kelas XI akuntasi SMK Negeri 1 Rengat. Data dalam penlitian ini didapatkan dari penilaian proses kegiatan belajar mengajar, hasil belajar siswa berupa nilai test formatif dan dokumen portofolio. Dari hasil penelitian didapatkan data bhawa terjadi perubahan dalam aspek keaktifan belajar siswa. pembelajaran dengan model ini mencakup tiga ranah pengetahuan yaitu (1)Afektif, (2) Kognitif dan (3) Psikomotor.
\end{abstract}

Kata kunci: Prestasi Belajar, Bertukar Pasangan, Akuntansi, Hasil belajar

\begin{abstract}
The purpose of this study was to improve student learning outcomes for the implementation of the learning matrices of the learning program of partner exchange models in class XI students of accounting at SMK Negeri 1 Rengat. The research used is a class action research conducted in 3 cycles. The subjects in this study were students of class XI accounting at SMK Negeri 1 Rengat. The data in this research are produced from the assessment of teaching and learning process, student learning outcomes contain formative test scores and document portfolios. From the research results, it was obtained that there was a change in the field of student learning activities. Learning with this model contains three domains of knowledge, namely (1) Affective, (2) Cognitive and (3) Psychomotor.
\end{abstract}

Keywords: Learning Achievemnet, Couple Eexchange, Learning Outcome.

\section{Pendahuluan}

Belajar dalam pandangan teori moderen adalah merupakan proses perubahan tingkah laku berkat intgeraksi dengan lingkungan. Jadi seseorang dikatakan melaukan kegiatan belajar, setelah ia memperoleh hasil yaitu terjadinya perubahan. Misalnya: dari tidak tahu menjadi tahu, dari tidak mengerti menjadi mengerti. Yang menjadi petunjuk bahwa suatu proses belajar bahwa suatu proses belajar mengajar dianggap berhasil apabila : daya serap terhadap bahan pengajaran yang diajarkan mencapai prestasi tinggi baik secara individual maupun kelompok.

Keberhasilan pembelajaran, dalam arti tercapainya tujuan-tujuan instruksional, sangat bergantung pada kemampuan guru mengelola proses belajar mengajar, proses belajar mengajar yang baik dapat menciptakan situasi yang memungkinkan anak belajar sehingga merupakan titik awal keberhasilan pembelajaran[1]. Selain itu tergantung juga kepada beberapa hal yang dapat mempengaruhi proses belajar mengajar antara lain kesiapan belajar, interaksi antar siswa, interaksi siswa dan guru, mengumpulkan tugas tepat waktu, mengerjakan tugas sesuai dengan petunjuk dan tidak menyontek. 
Dalam hal kesiapan belajar siswa sangat dipengaruhi oleh kondisi siswa itu sendiri. Siswa-siswi di SMK N 1 Rengat sebagian besar berada di daerah yang jauh dari fasilitas belajar yang memadai sehingga daya pikirnya berbeda dengan siswa-siswi yang berada di kota-kota yang banyak menyediakan failitas-fasilitas belajar yang memadai. Untuk interaksi antar siswa tidak begitu bermasalah namun untuk interaksi siswa dan guru masih perlu ditingkatkan lagi sehingga proses belajar mengajar dapat lebih effektif dan hasilnya berupa prestasi, daya serap dapat meningkat. Dalam hal mengumpulkan tugas yang diberikan guru, siswa masih kurang bertanggung jawab ditandai dengan mengumpulkan tugas tidak tepat pada waktunya. Sedangkan untuk pemahaman terhadap petunjuk yang diberikan oleh guru pembimbing terkadang siswa kurang begitu memperhatikan sehingga hasilnya tidak sesuai dengan yang diharapkan.

Dengan memperhatikan hal-hal yang telah diuraikan diatas maka perlu dicari suatu model pembelajaran yang dapat memudahkan siswa dalam menyerap pengetahuan yang diberikan oleh gurunya, dalam hal ini model pembelajaran bertukar pasangan diharapkan dapat meningkatkan daya serap siswa terhapat matadiklat Mengoperasikan paket pengolahan angka, yang mana matadiklat Mengoperasikan paket pengolahan angka termasuk pengetahuan yang bersifat teori dan deklaratif/Praktek sehingga akan lebih mudah dipahami bila dipelajari secara bersama-sama. dapat diajarkan.

Model pembelajaran bertukar pasangan adalah cara atau teknik pembelajaran yang digunakan oleh guru saat menyajikan bahan pelajaran. Dimana guru pemeran utama dalam menciptakan situasi interaktif yang edukatif, yakni interaktif antara guru dengan siswa dan dengan sumber pembelajaran dalam menunjang tercapainya tujuan belajar. Model pembelajaran bertukar pasangan termasuk pembelajaran dengan tingkat mobilitas cukup tinggi, dimana siswa akan bertukar pasangan dengan pasangan lainnya dan natinya harus kembali ketingkat semula/ pertamanya [2]. Model pembelajaran bertukar pasangan ini merupakan salah satu pembelajaran kooperatif yaitu pembelajaran yang dikembangkan dari teori kontruktivisme karena mengembangkan struktur kognitif untuk membangun pengetahuan sendiri melalui berpikir rasional [3]. Adapun langkah-langkah model pembelajaran bertukar pasangan diantaranya adalah sebagai berikut.

Tabel 1. Tahapan Pelaksanaan Model Pembelajaran Bertukar Pasangan

\begin{tabular}{|c|c|c|}
\hline No & Langkah & Kegiatan \\
\hline 1. & Pendahuluan & $\begin{array}{ll}\text { a. } & \text { Salam } \\
\text { b. } & \text { Doa } \\
\text { c. } & \text { Absensi } \\
\text { d. } & \text { Apersepsi } \\
\text { e. } & \text { Tanya jawab }\end{array}$ \\
\hline 2. & Kegiatan inti & $\begin{array}{l}\text { a. Pemberian penjelasan/konsep } \\
\text { b. Pembagian (pembentukan) pasangan } \\
\text { c. Pemberian tugas } \\
\text { d. Bertukar pasangan } \\
\text { e. Mencari kepastian jawaban pada pasangan baru } \\
\text { f. Kembali kepasangan semula untuk berbagi } \\
\text { informasi } \\
\text { g. Guru dan siswa menyimpulkan bersama-sama } \\
\text { h. Pemberian kesempatan bertanya }\end{array}$ \\
\hline 3. & Penutup & $\begin{array}{l}\text { a. Guru dan siswa menyimpulkan } \\
\text { b. Pemberian nasehat } \\
\text { c. Doa dan penutup }\end{array}$ \\
\hline
\end{tabular}


Berdasarkan uraian tersebut diatas bahwa pembelajaran Spreadsheet atau aplikasi pengelolaan angka pada komputer akuntansi sangat menjemukan kalau menggunakan model pembelajaran yang konvensional karena pada pembelajaran ini perlu adanya teman untuk saling memberikan masukan satu sama lainnya dengan kata lain untuk saling bertukar pikiran dalam menyelesaikan latihan soal. Maka diharapkan melalui model pembelajaran Bertukar pasangan ini dapat meningkatkan daya serap siswa terhadap mata diklat paket pengelolaan angka.

\section{Metode Penelitian}

\subsection{Waktu dan Tempat}

Penelitian tindakan ini dilaksanakan tahun 2015 secara terjadwal selama tiga bulan dimulai dari bulan Agustus s/d bulan Oktober. Mata pelajaran mengoperasikan program pengolahan angka menurut KTSP pelaksanaanya ditetapkan dua kali empat puluh lima menit dalam satu pekan. Penelitian ini dilaksanakan sesuai dengan jadwal yang telah disusun oleh wakil kurikulum di SMK Negeri 1 Rengat. Jadwal penelitiannya dilaksanakan dengan tiga siklus pertama dua kali pertemuan, siklus kedua-dua kali pertemuan. Pada pertemua ke dua dilakukan ujian sub sumatif, guna untuk mengukur kemamapuan siswa-siswi terhadap materi pelajaran yang sudah dilakukan, dengan model pembelajaran yang dilakukan.

Tabel 2. Waktu Pelaksanaan Kegiatan

\begin{tabular}{lllllll}
\hline Jam & \multicolumn{2}{c}{ SIKLUS I } & \multicolumn{2}{c}{ SIKLUS II } & \multicolumn{1}{c}{ SIKLUS III } \\
\cline { 2 - 4 } ke & Pertemuan 1 & Pertemuan 2 & Pertemuan 3 & Pertemuan 4 & Pertemuan 5 & Pertemuan 6 \\
& Selasa & Selasa & Selasa & Selasa & Selasa & Selasa \\
& $4 \quad$ Agustus & 11 Agustus & 8 September & 22September & 29September & $6,13,21$ \\
& 2015 & 2015 & 2015 & 2015 & 2015 & Oktober 2015 \\
$\mathbf{1}$ & & & & & & \\
$\mathbf{2}$ & & & & & & \\
$\mathbf{3}$ & XI AKT 3 & XI AKT 3 & XI AKT 3 & XI AKT 3 & XI AKT 3 & XI AKT 3 \\
$\mathbf{4}$ & XI AKT 3 & XI AKT 3 & XI AKT 3 & XI AKT 3 & XI AKT 3 & XI AKT 3 \\
$\mathbf{5}$ & & & & & & \\
$\mathbf{6}$ & & & & & & \\
\hline
\end{tabular}

\subsection{Subjek Penelitian}

Subyek penelitian ini adalah siswa SMK Negeri 1 Rengat. kelas XI Akuntansi 3. Jumlah sebanyak 34 siswa dengan komposisi terdiri dari peremuan 16 orang laki-laki 18 orang, peneliti mengambil kelas ini sebagai subjek penelitian karena kelas ini cukup mewakili dari jumlah siswa XI akuntansi SMK Negeri 1 Rengat.

\subsection{Sumber dan Teknik Pengumpulan Data}

Data dari penelitian tindakan ini akan penulis ambil dari tiga sumber yaitu; Proses Kegiatan Belajar Mengajar, Hasil Belajar Siswa berupa Nilai Test Formatif dan Dokumen portofolio. Dalam kelompok belajar ditunjuk dan diatur oleh guru.tujuannya agar dalam satu kelompok diatur siswa-siswinya dengan tingkat kemampuan yang berbeda-beda, agar siswasiawi yang kurang mampu termotivasi untuk meningkatkan kemampuan, meningkatkan keaktifannya mempelajari rumus-rumus tematika yang ada pada spreadsheet untuk menggunakannya pada akuntansi dan meningkatkan tanggung jawab.

\section{Hasil dan Pembahasan}

\subsection{Deskripsi Lingkungan Sekolah}

Penelitian ini dilaksanakan di SMK Negeri 1 Rengat. SMK Negeri 1 Rengat pada tahun 2015 beralamat di jalan Sultan Km 4. Kelurahan Nara Singa Kecamatan Rengat, Kabupaten Indragiri Hulu, Propinsi Riau. Dipimpin oleh bapak Drs.H. Adimirwan Nip. 19650801 
1995121001. Wakil Kepala Sekolah terdiri dari: waka kurikulum. Waka bidang kesiswaan, waka bidang manajemen mutu, waka bidang sarana dan prasarana, waka humas /DUDI, waka Sumber Daya Manusia, waka bidang lingkungan hidup.Staf pengajar baik PNS maupun Honor berjumlah 81 orang. Guru Bimbingan Konseling terdiri tujuh orang konselor. Staf keamanan 3 orang dan satpol PP 3 orang.

Tabel 3. Sebaran Rombel Setiap Diklat di SMK Negeri 1 Rengat

\begin{tabular}{|c|c|c|c|}
\hline No & Program keahlian & Kelas & Rombel \\
\hline \multirow[t]{3}{*}{1} & Keuangan & $\mathrm{X}$ & 3 Rombel \\
\hline & & XI & 3 Rombel \\
\hline & & XII & 3 Rombel \\
\hline \multirow[t]{3}{*}{2} & Administrasi & $\mathrm{X}$ & 3 Rombel \\
\hline & & XI & 3 Rombel \\
\hline & & XII & 3 Rombel \\
\hline \multirow[t]{3}{*}{3} & Tata Niaga & $X$ & 2 Rombel \\
\hline & & XI & 2 Rombel \\
\hline & & XII & 1Rombel \\
\hline \multirow[t]{3}{*}{4} & Teknik Komputer Jaringan & $X$ & 2 Rombel \\
\hline & & XI & 2 Rombel \\
\hline & & XII & 2 Rombel \\
\hline \multirow[t]{4}{*}{5} & Tata Busana & $\mathrm{X}$ & 1 Rombel \\
\hline & & XI & 1 Rombel \\
\hline & & XII & 1Rombel \\
\hline & Jumlah rombel & & 32 Rombel \\
\hline
\end{tabular}

\subsection{Hasil Pelaksanaan Tindakan}

\subsubsection{Siklus 1}

Pada siklus 1, petemuan pertama pembelajaran hari ini mengerjakan praktek spreadsheet di komputer belum dapat dikerjakan dengan teratur mengerjakannya dengan model betukar pasangan dalam tiga kelompok, satu kelompok terdiri dari 2 orang dalam arti satu komputer ditempati oleh dua orang. Jadi mereka bertukar pasangangan untuk tiga komputer mengerjakan satu siklus akuntansi secara bergantian dengan tanggung jawab masing-masing tugas belum dapat mengerjakan tugasnya dengan sempurna. Untuk itu pada pertemuan kedua siklus 1( pertama) akan diperbaiki lagi agar lebih efektif belajar dengan model pembelajaran yang dilakukan. Berdasarkan hasil pengumpulan data pada Siklus I, pertemuan pertama dan pertemuan kedua maka diperoleh rekapitulasi sebagai berikut. 
Tabel 4. Rekapitulasi Data Pengamatan Proses Belajar pada Siklus 1 Pertemuan Pertama

\begin{tabular}{llcccc}
\hline NO & \multicolumn{1}{c}{ AKTIVITAS } & N siswa & \multicolumn{3}{c}{ SCORE } \\
\cline { 4 - 6 } $\mathbf{1}$ & & & $\mathrm{A}$ & $\mathrm{B}$ & $\mathrm{C}$ \\
$\mathbf{2}$ & Kesiapan belajar & 34 & 0 & 14 & 20 \\
$\mathbf{3}$ & Interaksi antarsiswa & 34 & 1 & 13 & 20 \\
$\mathbf{4}$ & Menteraksi siswa guru & 34 & 0 & 0 & 34 \\
$\mathbf{5}$ & Mengerjakan tugas sesuai petunjuk & 34 & 0 & 2 & 32 \\
$\mathbf{6}$ & Tidak menyontek & 34 & 0 & 7 & 27 \\
& Jumlah & 34 & 0 & 31 & 3 \\
Presentasi & 204 & 1 & 67 & 136 \\
& & $100 \%$ & $0,49 \%$ & $32,84 \%$ & $66,67 \%$ \\
\hline
\end{tabular}

Tabel 5. Rekapitulasi Data Pengamatan Proses Belajar pada Siklus 1 Pertemuan Kedua

\begin{tabular}{|c|c|c|c|c|c|}
\hline \multirow[t]{2}{*}{ NO } & \multirow[t]{2}{*}{ AKTIVITAS } & \multirow[t]{2}{*}{$\sum$ siswa } & \multicolumn{3}{|c|}{ SCORE } \\
\hline & & & $\mathrm{A}$ & $\mathrm{B}$ & $\mathrm{C}$ \\
\hline 1 & Kesiapan belajar & 34 & 0 & 13 & 21 \\
\hline 2 & Interaksi antarsiswa & 34 & 1 & 13 & 20 \\
\hline 3 & Interaksi siswa guru & 34 & 0 & 2 & 32 \\
\hline 4 & Mengumpulkan tugas tepat waktu & 34 & 0 & 5 & 29 \\
\hline 5 & Mengerjakan tugas sesuai petunjuk & 34 & 0 & 16 & 18 \\
\hline 6 & Tidak menyontek & 34 & 2 & 30 & 2 \\
\hline & Jumlah & 204 & 3 & 79 & 122 \\
\hline \multicolumn{2}{|c|}{ Presentasi } & $100 \%$ & $1,47 \%$ & $38,73 \%$ & $59,80 \%$ \\
\hline
\end{tabular}

Untuk hasil belaar peserta didik pada siklus I dalam penerapan model pembalajran bertukar pasangan dilaksanakan pada setiap akhir pertemuan. Untuk pengukuran hasil beljar menggunakan instrumen hasil belajar berupa soal formatif dengan jumlah 20 butir. Adapun deskripsi hasil beajar pada iklus I dapat dilihat pada grafik berikut.

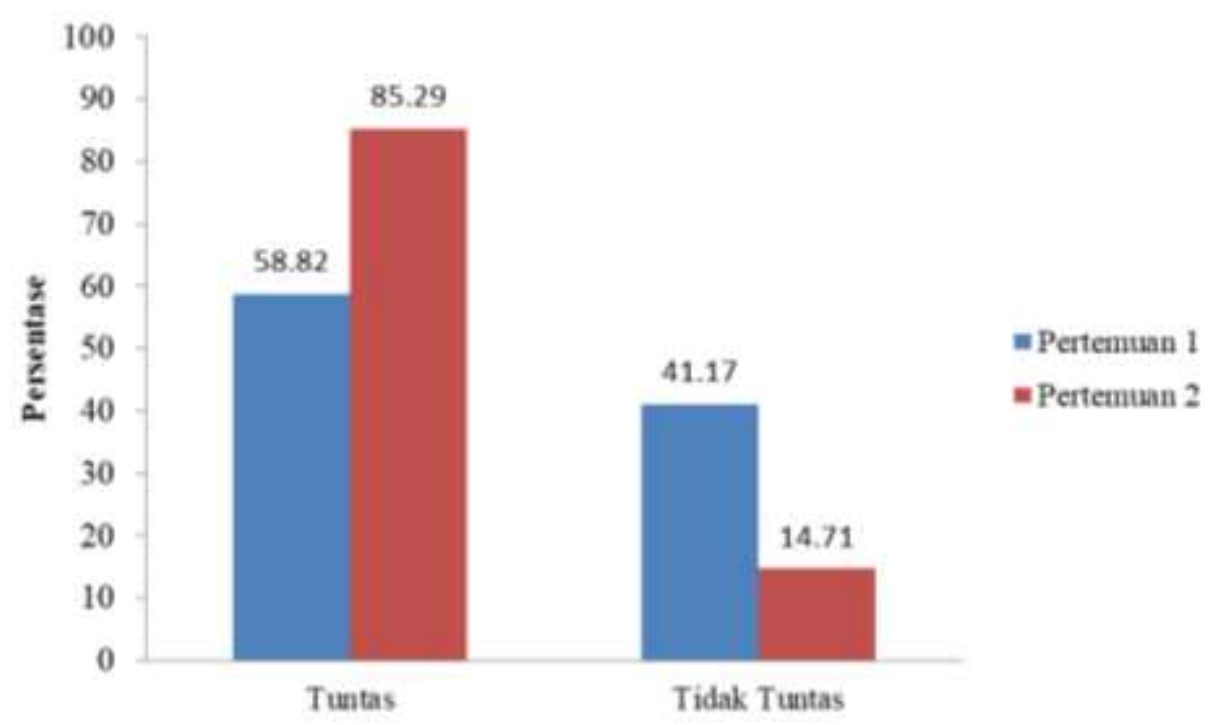

Gambar 1. Grafik Penigkatan Hasil Belajar pada Siklus 1 


\subsubsection{Siklus 2}

Pada siklus II, petemuan pertama pembelajaran adalah mengerjakan praktek spreadsheet di komputer belum dapat dikerjakan dengan teratur mengerjakannya dengan model betukar pasangan dalam tiga kelompok, satu kelompok terdiri dari 2 orang dalam arti satu komputer ditempati oleh dua orang. Jadi mereka bertukar pasangangan untuk tiga komputer mengerjakan satu siklus akuntansi secara bergantian dengan tanggung jawab masing-masing tugas belum dapat mengerjakan tugasnya dengan sempurna. Untuk itu pada pertemuan kedua siklus 1( pertama) akan diperbaiki lagi agar lebih efektif belajar dengan model pembelajaran yang dilakukan. Berdasarkan hasil pengumpulan data pada Siklus II, pertemuan pertama dan pertemuan kedua maka diperoleh rekapitulasi sebagai berikut.

Tabel 6. Rekapitulasi Data Pengamatan Proses Belajar pada Siklus 2 Pertemuan Ketiga

\begin{tabular}{llcccc}
\hline \multirow{2}{*}{ NO } & \multicolumn{1}{c}{ AKTIVITAS } & $\sum$ siswa & $\mathrm{A}$ & $\mathrm{B}$ & $\mathrm{C}$ \\
\cline { 3 - 5 } $\mathbf{1}$ & Kesiapan belajar & 34 & 1 & 12 & 21 \\
$\mathbf{2}$ & Interaksi antarsiswa & 34 & 0 & 10 & 24 \\
$\mathbf{3}$ & Interaksi siswa guru & 34 & 3 & 6 & 25 \\
$\mathbf{4}$ & Mengumpulkan tugas tepat waktu & 34 & 0 & 8 & 26 \\
$\mathbf{5}$ & Mengerjakan tugas sesuai petunjuk & 34 & 0 & 11 & 23 \\
$\mathbf{6}$ & Tidak menyontek & 34 & 3 & 27 & 4 \\
& Jumlah & 204 & 7 & 74 & 123 \\
& Presentasi & $100 \%$ & $3.43 \%$ & $36.27 \%$ & $60.29 \%$ \\
\hline
\end{tabular}

Tabel 7. Rekapitulasi Data Pengamatan Proses Belajar pada Siklus 2 Pertemuan Keempat

\begin{tabular}{llcccc}
\hline & \multicolumn{1}{c}{ AKTIVITAS } & & \multicolumn{3}{c}{ SCORE } \\
\cline { 4 - 6 } $\mathbf{1}$ & Kesiapan belajar & & $\mathrm{A}$ & $\mathrm{B}$ & $\mathrm{C}$ \\
$\mathbf{2}$ & Interaksi antarsiswa & 34 & 19 & 10 & 5 \\
$\mathbf{3}$ & Interaksi siswa guru & 34 & 9 & 20 & 5 \\
$\mathbf{4}$ & Mengumpulkan tugas Tepat waktu & 34 & 19 & 9 & 6 \\
$\mathbf{5}$ & Mengerjakan tugas sesuai petunjuk & 34 & 19 & 8 & 7 \\
$\mathbf{6}$ & Tidak menyontek & 34 & 10 & 18 & 6 \\
& Jumlah & 20 & 12 & 2 \\
& Presentasi & $100 \%$ & $47,06 \%$ & $37,74 \%$ & $15,20 \%$ \\
\hline
\end{tabular}

Dari Observasi dan hasil pengamatan yang dimasukkan dalam rekapitulasi tersebut diatas diperoleh hasil penilaian bahwa untuk pengamatan proses belajar kesiapan belajar, Interaksi antar siswa, interaksi siswa guru, mengumpulkan tugas tepat waktu, mengerjakan tugas sesuai petunjuk dan tidak menyontek scorenya sudah menunjukkan peningkatan. Demikian juga untuk penilaian dokumen hasil kerja kelompok dengan kreteria Ketelitian, kesesuaian dengan tugas, kebenaran jawaban dan tanggung jawab scorenya juga sudah menunjukkan peningkatan. Dari hasil sumatif observasi pekerjaan masing-masing siswa dapat dilihat dengan penilaian meningkat rata-rata memperoleh nilai 80 keatas, 28 orang yaitu $76 \%$, memperoleh nilai 75-79, 4 orang $14.71 \%$, memperoleh nilai dibawah KKM 2 orang yaitu 2.94 $\%$. 


\subsubsection{Siklus III}

Pada siklus II, petemuan pertama pembelajaran adalah mengerjakan praktek spreadsheet di komputer belum dapat dikerjakan dengan teratur mengerjakannya dengan model betukar pasangan dalam tiga kelompok, satu kelompok terdiri dari 2 orang dalam arti satu komputer ditempati oleh dua orang. Jadi mereka bertukar pasangangan untuk tiga komputer mengerjakan satu siklus akuntansi secara bergantian dengan tanggung jawab masing-masing tugas belum dapat mengerjakan tugasnya dengan sempurna. Untuk itu pada pertemuan kedua siklus III( pertama) akan diperbaiki lagi agar lebih efektif belajar dengan model pembelajaran yang dilakukan. Berdasarkan hasil pengumpulan data pada Siklus III, pertemuan kelima dan pertemuan keenam maka diperoleh rekapitulasi sebagai berikut.

Tabel 8. Rekapitulasi Data Pengamatan Proses Belajar pada Siklus 3 Pertemuan Kelima

\begin{tabular}{|c|c|c|c|c|c|}
\hline \multirow{2}{*}{ NO } & \multirow{2}{*}{ AKTIVITAS } & \multirow{2}{*}{$\sum$ siswa } & \multicolumn{3}{|c|}{ SCORE } \\
\hline & & & $\mathrm{A}$ & $\mathrm{B}$ & $\bar{C}$ \\
\hline 1 & Kesiapan belajar & 34 & 26 & 7 & 1 \\
\hline 2 & Interaksi antarsiswa & 34 & 28 & 4 & 2 \\
\hline 3 & Interaksi siswa guru & 34 & 19 & 9 & 6 \\
\hline 4 & Mengumpulkan Tugas Tepat waktu & 34 & 30 & 4 & 0 \\
\hline 5 & Mengerjakan tugas sesuai petunjuk & 34 & 27 & 6 & 1 \\
\hline 6 & Tidak menyontek & 34 & 29 & 5 & 0 \\
\hline & Jumlah & 204 & 159 & 35 & 10 \\
\hline & Presentasi & $100 \%$ & $77.94 \%$ & $17.16 \%$ & $4.90 \%$ \\
\hline
\end{tabular}

Untuk hasil belajar peserta didik pada siklus III mengalami peningkatan dibandingkan hasil belajar pada siklus II dan Siklus I. Untuk penilaian dokumen hasil kerja kelompok dengan kreteria Ketelitian, Kesesuaian dengan tugas, Kebenaran jawaban dan Tanggung jawab scorenya juga sudah menunjukkan peningkatan sesuai dengan yang diharapkan diperoleh hasil subsumatif observasi pekerjaan masing-masing siswa dapat dilihat dengan penilaian meningkat rata-rata memperoleh nilai 80 keatas. Adapun grafik peningkatan hasil belajar peserta didik dapat ditampilkan dalam gambar berikut.

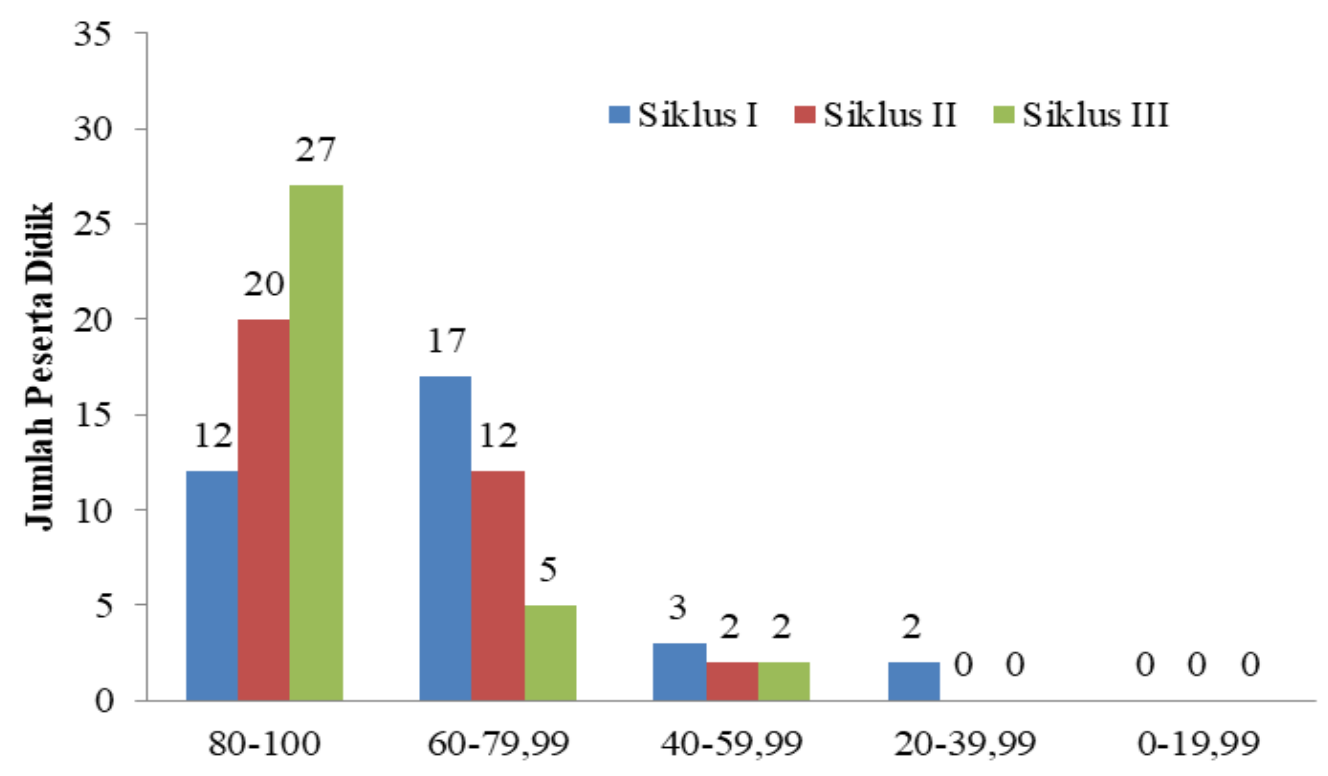

Gambar 2. Peningkatan Hasil Belajar pada Model Bertukar Pasangan 


\subsection{Pembahasan}

Tindakan Siklus III ternyata mampu mengubah sikap belajar siswa terutama pada saat mengikuti kegiatan belajar mengajar dan mampu meningkatkan motivasi siswa untuk belajar sehingga hasil belajar siswa meningkat serta dapat terlihat bahwa daya serap siswa terhadap mata diklat aplikasi pengolahan angka ( spreadsheet)di Komputer semakin meningkat. Kegiatan belajar yang menggunakan alat praktek (Komputer) sangat menarik bagi siswa. Pembelajaran dengan Bertukar Pasangan merupakan model yang sangat baik untuk meningkatkan keaktifan belajar siswa [4]. Hal ini karena pembelajaran dengan model ini mencakup tiga ranah pengetahuan yaitu (1) Afektif, (2) Kognitif dan (3) Psikomotor. Materi-materi yang disajikan dengan model ini mudah diingat dan dipahami siswa. pembelajaran kooperatif memiliki peran dan manfaat yang besar bagi siswa. Dengan menerapkan model pembelajaran kooperatif ini siswa akan terlibat aktif dalam kelompok untuk bersama-sama memecahkan soal yang diberikan guru [5].

Tabel 9. Rekapitulasi Pelaksanaan Kegiatan

\begin{tabular}{|c|c|c|c|c|c|c|c|c|c|}
\hline \multirow[t]{2}{*}{ No } & \multirow[t]{2}{*}{ Aspek } & \multirow[t]{2}{*}{ Skor } & \multicolumn{2}{|c|}{ Siklus pertama } & \multicolumn{2}{|c|}{ Siklus kedua } & \multicolumn{2}{|c|}{ Siklus ketiga } & \multirow[t]{2}{*}{$\%$} \\
\hline & & & Pert 1 & Pert 2 & Pert 3 & Pert 4 & Pert 5 & Pert 6 & \\
\hline \multirow[t]{4}{*}{1} & Aktifitas & A & 1 & 3 & 7 & 96 & 110 & 159 & 77.94 \\
\hline & & B & 67 & 79 & 74 & 77 & 77 & 35 & 17.16 \\
\hline & & $\mathrm{C}$ & 136 & 122 & 123 & 31 & 17 & 10 & 4.90 \\
\hline & Skor max & 204 & & & & & & & \\
\hline \multirow[t]{4}{*}{2} & Kerja & A & 0 & 0 & 7 & 34 & 40 & 10 & 92.67 \\
\hline & Kelompok & B & 10 & 17 & 29 & 9 & 5 & 2 & 8.33 \\
\hline & & $\mathrm{C}$ & 32 & 31 & 12 & 5 & 3 & 0 & 0 \\
\hline & Skor max & 48 & & & & & & & \\
\hline \multirow[t]{2}{*}{3} & Hasil & $\mathrm{T}$ & & 29 org & & 32 org & & 33 org & 97.06 \\
\hline & formatif & TT & & 5 org & & 2 org & & 1 org & 2.94 \\
\hline
\end{tabular}

Secara umum hasil tindakan pada siklus 3 dari hasil aktifitas, hasil observasi kerja kelompok oleh observer, dan hasil tes formatif, sumatif dapat dikatakan bahwa metode pembelajaran Bertukar Pasangan dapat meningkatkan daya serap siswa terhadap mata diklat Aplikasi pengolahan angka pada komputer mengerjakan Siklus Akuntansi yang ditandai dengan meningkatnya prestasi dan hasil belajar siswa.

\section{Kesimpulan}

Dari hasil pembahasan diatas disimpulkan data peningkatan kegiatan kreativitas peserta didik diantaranya terjadi perubahan dalam aspek keaktifan belajar siswa. pembelajaran dengan model ini mencakup tiga ranah pengetahuan yaitu (1)Afektif, (2) Kognitif dan (3) Psikomotor. Peningkatan Daya serap siswa terhadap mata diklat Aplikasi Pengolahan Angka di komputer dapat dilakukan dengan menggunakan pembelajaran Bertukar Pasangan. Akan lebih baik lagi bila satu computer satu orang. Pembelajaran Bertukar pasangan ternyata mampu meningkatkan perhatian siswa terhadap pokok bahasan yang diajarkan. Siswa terarahkan perhatiannya pada materi yang diajarkan dan mampu meningkatkan hasil belajar. Pembelajaran Bertukar pasangan dapat mengoptimalkan pemakaian sarana dan prasarana yang ada disekolah terutama pemakaian ruang praktek Komputer 


\section{Daftar Pustaka}

[1] E. P. Widoyoko, “Evaluasi Program Pembelajaran,” J. Ilmu Pendidik., 2000.

[2] D. T. Ayuni, "PENGGUNAAN STRATEGI PEMBELAJARAN PERMAINAN BERTUKAR PASANGAN UNTUK MENINGKATKAN MINAT BELAJAR SISWA KELAS X SMA UTAMA 2 BANDAR LAMPUNG TAHUN AJARAN 2015/2016,” IOSR J. Econ. Financ., 2016.

[3] S. Wulandari, S. Buwono, and R. Rosyid, "EFEKTIVITAS MODEL BERTUKAR PASANGAN PADA PERSAMAAN DASAR AKUNTANSI TERHADAP HASIL BELAJAR SISWA DI SMA," J. Pendidik. dan Pembelajaran, 2013.

[4] Kasnati, "MODEL PEMBELAJARAN BERTUKAR PASANGAN," Suara Guru J. Ilmu Pendidik. Sos. sains, dan Hum., vol. 2, no. 2, 2016.

[5] I. R. Hidayah, "PERBEDAAN MODEL BERTUKAR PASANGAN DENGAN MAKE A MATCH TERHADAP HASIL BELAJAR PECAHAN," J. Pendidik. Guru Sekol. Dasar, vol. 33, no. 7, pp. 283-290, 2018. 